NASA/TM-2005-213411

\title{
Overview of NASA Magnet and Linear Alternator Research Efforts
}

Steven M. Geng

Glenn Research Center, Cleveland, Ohio

Janis M. Niedra

QSS Group, Inc., Cleveland, Ohio

Gene E. Schwarze

Glenn Research Center, Cleveland, Ohio 
Since its founding, NASA has been dedicated to the advancement of aeronautics and space science. The NASA Scientific and Technical Information (STI) Program Office plays a key part in helping NASA maintain this important role.

The NASA STI Program Office is operated by Langley Research Center, the Lead Center for NASA's scientific and technical information. The NASA STI Program Office provides access to the NASA STI Database, the largest collection of aeronautical and space science STI in the world. The Program Office is also NASA's institutional mechanism for disseminating the results of its research and development activities. These results are published by NASA in the NASA STI Report Series, which includes the following report types:

- TECHNICAL PUBLICATION. Reports of completed research or a major significant phase of research that present the results of NASA programs and include extensive data or theoretical analysis. Includes compilations of significant scientific and technical data and information deemed to be of continuing reference value. NASA's counterpart of peerreviewed formal professional papers but has less stringent limitations on manuscript length and extent of graphic presentations.

- TECHNICAL MEMORANDUM. Scientific and technical findings that are preliminary or of specialized interest, e.g., quick release reports, working papers, and bibliographies that contain minimal annotation. Does not contain extensive analysis.

- CONTRACTOR REPORT. Scientific and technical findings by NASA-sponsored contractors and grantees.
- CONFERENCE PUBLICATION. Collected papers from scientific and technical conferences, symposia, seminars, or other meetings sponsored or cosponsored by NASA.

- SPECIAL PUBLICATION. Scientific, technical, or historical information from NASA programs, projects, and missions, often concerned with subjects having substantial public interest.

- TECHNICAL TRANSLATION. Englishlanguage translations of foreign scientific and technical material pertinent to NASA's mission.

Specialized services that complement the STI Program Office's diverse offerings include creating custom thesauri, building customized databases, organizing and publishing research results ... even providing videos.

For more information about the NASA STI Program Office, see the following:

- Access the NASA STI Program Home Page at http://www.sti.nasa.gov

- E-mail your question via the Internet to help@sti.nasa.gov

- Fax your question to the NASA Access Help Desk at 301-621-0134

- Telephone the NASA Access Help Desk at 301-621-0390

- Write to:

NASA Access Help Desk

NASA Center for AeroSpace Information 7121 Standard Drive

Hanover, MD 21076 
NASA/TM-2005-213411

\section{Overview of NASA Magnet and Linear Alternator Research Efforts}

Steven M. Geng

Glenn Research Center, Cleveland, Ohio

Janis M. Niedra

QSS Group, Inc., Cleveland, Ohio

Gene E. Schwarze

Glenn Research Center, Cleveland, Ohio

Prepared for the

Space Technology and Applications International Forum (STAIF-2005)

sponsored by the University of New Mexico's Institute for Space and

Nuclear Power Studies (UNM-ISNPS)

Albuquerque, New Mexico, February 13-17, 2005

National Aeronautics and

Space Administration

Glenn Research Center 


\section{Acknowledgments}

The authors wish to acknowledge the technical contributions of Dr. Reinhold M.W. Strnat of KJS Associates, Magnetic Instrumentation, Inc. Dr. Strnat designed and built the critical characterization fixtures used to measure the magnetic properties of the various magnet samples as discussed in this paper. The work described in this paper was performed for NASA Headquarters, Science Mission Directorate (Code S) under the auspices of Prometheus.

Trade names or manufacturers' names are used in this report for identification only. This usage does not constitute an official endorsement, either expressed or implied, by the National Aeronautics and Space Administration.

Available from

NASA Center for Aerospace Information 7121 Standard Drive

Hanover, MD 21076
National Technical Information Service 5285 Port Royal Road Springfield, VA 22100 


\title{
Overview of NASA Magnet and Linear Alternator Research Efforts
}

\author{
Steven M. Geng \\ National Aeronautics and Space Administration \\ Glenn Research Center \\ Cleveland, Ohio 44135 \\ Janis M. Niedra \\ QSS Group, Inc. \\ Cleveland, Ohio 44135 \\ Gene E. Schwarze \\ National Aeronautics and Space Administration \\ Glenn Research Center \\ Cleveland, Ohio 44135
}

\begin{abstract}
The Department of Energy, Lockheed Martin, Stirling Technology Company, and NASA Glenn Research Center are developing a high-efficiency, 110 watt Stirling Radioisotope Generator (SRG110) for NASA Space Science missions. NASA Glenn is conducting in-house research on rare earth permanent magnets and on linear alternators to assist in developing a free-piston Stirling convertor for the SRG110 and for developing advanced technology. The permanent magnet research efforts include magnet characterization, short-term magnet aging tests, and long-term magnet aging tests. Linear alternator research efforts have begun just recently at GRC with the characterization of a moving iron type linear alternator using GRC's alternator test rig. This paper reports on the progress and future plans of GRC's magnet and linear alternator research efforts.
\end{abstract}

\section{INTRODUCTION}

The Department of Energy (DOE), Lockheed Martin (LM) of Valley Forge, PA, Stirling Technology Company (STC) of Kennewick, WA, and NASA Glenn Research Center (GRC) are developing a high-efficiency, 110 watt Stirling Radioisotope Generator (SRG110) for possible use on future NASA Space Science missions (Cockfield and Chan, 2002) (Schreiber and Thieme, 2004). To assist in the development of a free-piston Stirling convertor for the SRG110, GRC is conducting in-house research on rare earth permanent magnets (REPM) and on linear alternators. The REPM research efforts include magnet characterization, short-term magnet aging tests, and long-term magnet aging tests.

Magnet characterization was performed on 1-cm cube neodymium-iron-boron rare earth permanent magnets obtained from various vendors. The remanence $\left(B_{r}\right)$, intrinsic coercivity $\left(H_{c i}\right)$ and the magnetization $(M)$ were measured for each of the magnet samples over the temperature range of $20{ }^{\circ} \mathrm{C}$ to $140{ }^{\circ} \mathrm{C}$.

Based on the results of the magnet characterization tests, several magnet grades were selected for the short-term magnet aging test. The short-term magnet aging test was a 200 hour test, with the magnet samples exposed to a temperature of $150{ }^{\circ} \mathrm{C}$ and a demagnetizing field of $-5.0 \mathrm{kOe}$. Magnet grades that suffered the least amount of magnetic property loss during the short-term magnet aging test were then subjected to the long-term magnet aging test. The long-term magnet aging test was originally scheduled to be a 12,000 hour test, with the magnet samples exposed to a temperature of $120^{\circ} \mathrm{C}$ and a demagnetizing field of $-6.0 \mathrm{kOe}$. The long-term magnet aging test was extended and lasted for 18,000 hours.

Although the magnet research efforts performed at GRC were conducted on 1-cm cubic magnet samples, a special arc-magnet fixture was designed and built to measure the intrinsic coercivity of the actual magnets used in a Stirling convertor application. Due to the nature of the magnet geometry, the accuracy of the $\mathrm{H}_{\mathrm{ci}}$ measurements on the Stirling power convertor magnets is less than that for the $1-\mathrm{cm}$ cubes. However, the arc-magnet fixture may be of 
use in performing a relative comparison between Stirling power convertor magnets to exclude those magnets that may lead to performance issues.

Linear alternator research efforts have begun at GRC with the characterization of a moving iron type linear alternator using GRC's alternator test rig (ATR). The linear alternator performance was mapped over a range of temperatures, mover amplitudes, and alternator loads. Performance measurements included the linear alternator terminal voltage, current, and power output. A load cell was incorporated in the linkage between the drive motor and the linear alternator to measure the alternator mechanical input power. The alternator efficiency was calculated from these measurements. The objective of these efforts is to gather information that could be used to improve future linear alternator designs.

\section{MAGNET CHARACTERIZATION}

Specialized test equipment is needed to characterize REPMs. A 1-cm cubic magnet is normally the sample geometry used to characterize the magnetic properties. The first step is to magnetize the sample in a process called charging. This is performed at GRC using a capacitor-discharge pulse magnetizer. The magnetic properties can then be measured using an electromagnet and a pair of sensing coils. One sensing coil is used to measure the field strength $(\mathrm{H})$ directly; the other sensing coil is used to measure the flux density from which magnetization (M) is derived using an analog processor. The B-H curve (normal induction curve) can then be calculated from the $\mathrm{M}-\mathrm{H}$ curve (intrinsic induction curve) using Equation (1).

$$
\mathrm{B}=\mathrm{H}+4 \pi \mathrm{M}
$$

Once the M-H and B-H curves are obtained, the magnet sample's magnetic properties such as remanence $\left(B_{r}\right)$, intrinsic coercivity $\left(\mathrm{H}_{\mathrm{ci}}\right)$ and coercivity $\left(\mathrm{H}_{\mathrm{c}}\right)$ are readily determined. Figure 1 shows a sample set of induction curves, indicating these parameters of interest while Fig. 2 shows apparatus used to measure induction curves.

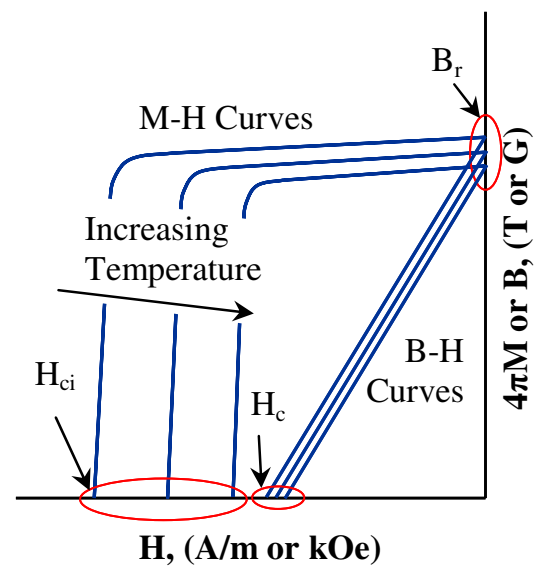

FIGURE 1. Sample Set of Demagnetization Curves.

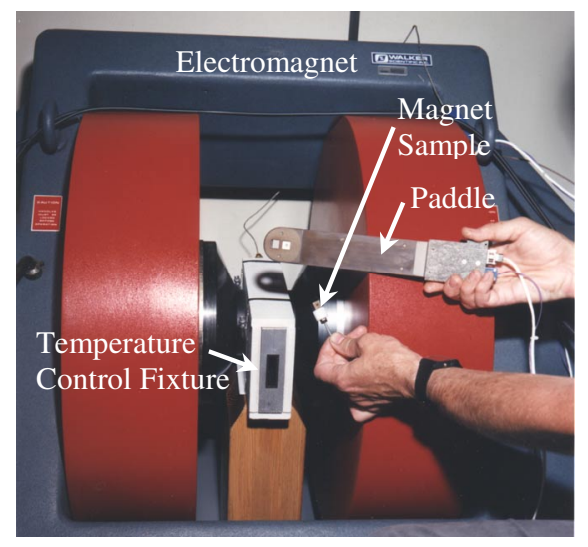

FIGURE 2. Magnet Characterization Paddle, TemperatureControl Fixture, and Electromagnet. A Magnet Sample is on Top of a Special Holder.

\section{Apparatus and Procedure}

A pulse magnetizer (Magnetic Instrumentation Inc., model 8687) of the mercury-ignitron-switched, capacitordischarge type was used to charge the magnet samples. Both samarium-cobalt ( $\mathrm{Sm}-\mathrm{Co}$ ) and neodymium-iron-boron (Nd-Fe-B) type magnets can be charged using this magnetizer. A maximum of $24 \mathrm{~kJ}$ can be stored at $2000 \mathrm{~V}$ on a $0.012 \mathrm{~F}$ capacitor bank of the magnetizer. This bank can be connected to either one of two solenoids, one providing peak fields up to $13 \mathrm{~T}$ in a 1 -in. bore and the other up to $10 \mathrm{~T}$ in a 1.75-in. bore. The 1 -in. bore solenoid was used for the characterization work discussed in this paper. 
The magnet samples were placed in an aluminum paddle fitted with built-in flux density and field strength sensing coils. The paddle can accommodate a single $1-\mathrm{cm}$ cubic magnet sample. The paddle with magnet sample was then inserted into a magnet sample temperature-control fixture, which was located between the flat and parallel poles of a 10-in., variable gap electromagnet (Walker Scientific, model HV-10V) equipped with tapered pole caps, as shown in Fig. 2. The temperaturecontrol fixture contains a heater element capable of controlling the magnet sample temperature up to $300{ }^{\circ} \mathrm{C} \pm 3{ }^{\circ} \mathrm{C}$. Figure 3 shows how a precision $1-\mathrm{cm}$ cubic sample fits closely between the parallel faces of iron-cobalt pole pieces that are precision mounted to the temperature-control fixture. The electromagnet was powered using four power amplifiers (Techron, model 7700) specially configured for the electromagnet. More information on GRC's magnet characterization experimental set-up is given by Niedra (1991).

The electromagnet was used to apply an external demagnetizing field on the magnet. While the external demagnetizing field was slowly increased until the magnet sample was demagnetized, the magnet's M-H data was recorded using a Hewlett-Packard (Agilent) 34970A data acquisition/switch unit. The data was then imported into Microsoft Excel where the B-H data was calculated

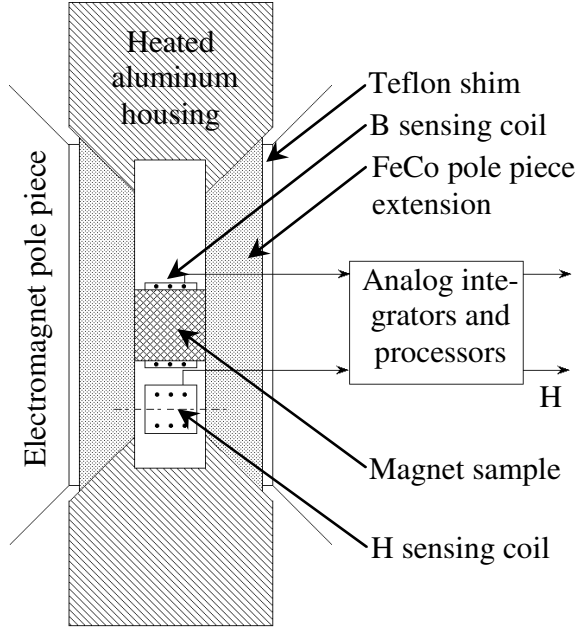

FIGURE 3. Schematic of Paddle, TemperatureControl Fixture, and Pole Caps. from the $\mathrm{M}-\mathrm{H}$ data and the demagnetization curves were plotted.

Magnet characterization is normally performed at GRC for one of three reasons: 1) to gain insight into how a magnet will perform at various temperatures, 2) to measure the magnetic properties prior to conducting a magnet aging test, or 3 ) to measure the magnetic properties at the conclusion of a magnet aging test. If a $1-\mathrm{cm}$ cubic magnet sample is being characterized for reasons one or two, the sample is first placed in the magnet charger where it is exposed to generally three, $13 \mathrm{~T}$ magnetic flux density pulses. The first pulse will charge the magnet sample to at or near its maximum magnetic flux density, while the second and third pulses are used to ensure maximum magnetization.

\section{MAGNET AGING TESTS}

The magnet aging tests were performed on 1-cm cubic magnet samples in helium, at elevated temperature, and also under an externally applied demagnetizing field. To date, only Nd-Fe-B magnet samples have been age tested at GRC. Currently, only one magnet aging fixture is available. A second, higher temperature magnet aging fixture, nearly identical to the first fixture, is being developed to perform magnet aging tests on Nd-Fe-B as well as Sm-Co magnets.

Two different types of magnet aging tests were conducted at GRC: short-term and long-term. The short-term magnet aging test is a 200 hour test, while the long-term test is intended for 12,000 hours or more.

\section{Apparatus and Procedure}

Both the short-term and long-term magnet aging tests utilize the same equipment. The key components of the magnet aging apparatus include a magnet aging fixture, an electromagnet, a power supply, and a turbopump for internal fixture clean-up. The magnet aging fixture, as shown in Figures 4 and 5, controls the sample temperature, can hold a vacuum or an inert gas, and can accommodate up to 10 magnet samples between 4-in. diameter, ironcobalt alloy pole pieces. This fixture holds the magnets in fixed positions, distributed over the pole face, so as to minimize any sample-to-sample field interference. The fixture is capable of maintaining a demagnetizing field uniform within 5 percent over the pole face areas. The demagnetizing field was supplied by a GMW, Inc., model 3472, 4-in. electromagnet energized by a Kepco 20-20M bipolar power supply/amplifier. A Pfeiffer turbopump 
capable of $10^{-10} \mathrm{~mm}$ of $\mathrm{Hg}$ was used to provide a clean-up vacuum for the magnet samples prior to helium fill and aging. Figure 6 shows the magnet aging fixture installed in the electromagnet.

In the short-term magnet aging test, the Nd-Fe-B magnet samples were held at $150{ }^{\circ} \mathrm{C}$ in helium while exposed to a $-5.0 \mathrm{kOe}$ demagnetizing field. The $150{ }^{\circ} \mathrm{C}$ short-term magnet aging temperature was chosen somewhat arbitrarily to accelerate aging, but is still within the manufacturers' temperature limits for the magnets. At this temperature, a -5.0 kOe demagnetizing field was found to drive the magnets tested to a point just short of demagnetization. In other words, the operating point of the magnets in the short-term aging test was close to the knee of the M-H curve in the 2nd quadrant as shown in Figure 7.

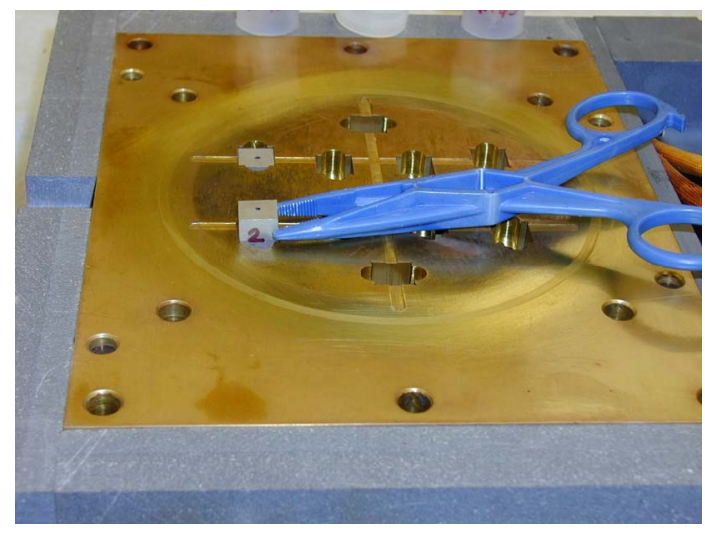

FIGURE 4. Magnet Aging Fixture Sample Holding Plate with two Magnet Samples.

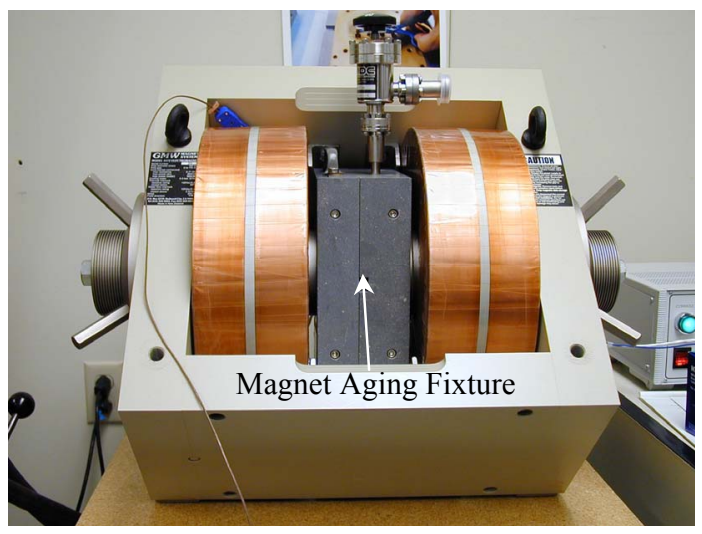

FIGURE 6. Magnet Aging Fixture Installed in Electromagnet.

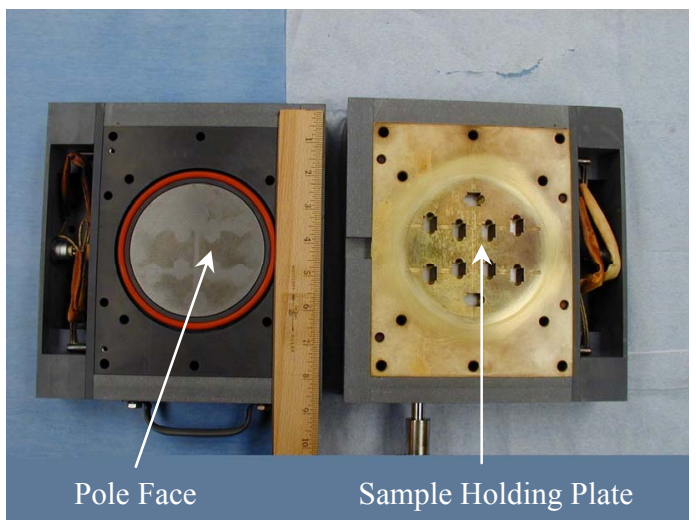

FIGURE 5. Separated Magnet Aging Fixture, Showing One Pole Extension.

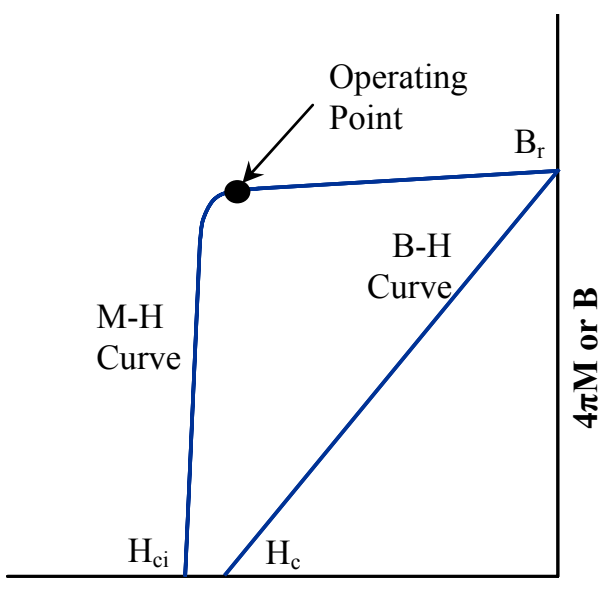

$\mathbf{H}$

FIGURE 7. Magnet Operating Point During Aging Test.

In the long-term magnet aging test, the Nd-Fe-B magnet samples were held at $120^{\circ} \mathrm{C}$ in helium while exposed to a -6.0 kOe demagnetizing field. The $120{ }^{\circ} \mathrm{C}$ long-term magnet aging temperature was also chosen somewhat arbitrarily, as a temperature sufficiently above the expected real use temperature in a Stirling linear alternator application to provide an adequate thermal margin. At this temperature, a $-6.0 \mathrm{kOe}$ demagnetizing field was also found to drive the magnets tested to a point just short of demagnetization. It should be noted that future long-term demagnetization tests will also be conducted at temperatures of $120^{\circ} \mathrm{C}$, but the external demagnetizing field may be different. The strength of the external demagnetizing field needed to drive the magnet samples to a point just short of demagnetization depends upon the $\mathrm{M}-\mathrm{H}$ characteristics of the magnets being tested.

Magnet aging was measured by comparing a magnet's pre-aging characterization data $\left(\mathrm{B}_{\mathrm{r}}\right.$ and $\left.\mathrm{H}_{\mathrm{c}}\right)$ with its postaging characterization data. The important magnetization loss data is the decrease in $\mathrm{B}_{\mathrm{r}}$ while the important measure 
of loss in resistance to demagnetization is the decrease in $\mathrm{H}_{\mathrm{ci}}$. After post-aging magnet characterization, the magnet samples were recharged, and then re-characterized to see if any permanent changes had occurred during the aging test. Non-recovery of the original $\mathrm{B}_{\mathrm{r}}$ and $\mathrm{H}_{\mathrm{ci}}$ after recharge indicates a metallurgical change.

\section{Summary of Results}

Two types of anisotropic, Nd-Fe-B magnets were selected for short-term aging from each of 3 manufacturers:

Vacuum Schmeltze (VAC): $\quad 383 \mathrm{HR}, 396 \mathrm{HR}$

Ugimag: $\quad 38 \mathrm{KC} 2,40 \mathrm{HC} 2$

Magnequench: $\quad$ MQ3-F36, MQ3-F42

To fill the ten sample slots in the magnet aging fixture, two samples of each of the two Ugimag and two Magnequench types and one sample of each of the two VAC types were selected based on their characterization data.

After the short-term aging test was completed, the magnetic properties of the magnet samples were measured and compared with the initial values. The loss in remanence was less than or equal to 1 percent for $396 \mathrm{HR}, 40 \mathrm{HC} 2$, and $38 \mathrm{KC} 2$, while the loss in remanence was greater than or equal to 2 percent for 383HR, MQ3-F36, and MQ3-F42. The loss in intrinsic coercivity was between 1 to 2 percent for all samples except for MQ3-F42, which suffered a loss of over 3 percent. Based on the results of the short-term aging test, $40 \mathrm{HC} 2$ and $38 \mathrm{KC} 2$ were selected for the long-term aging test. Restriction to just two magnet types for the long-term aging run allowed for five samples of each type in the ten-sample aging fixture. A full description of this work is given by Niedra (2001).

\section{INTRINSIC COERCIVITY MEASUREMENTS FOR ARC-SHAPED MAGNETS}

An arc-magnet characterization paddle was fabricated to measure the M-H curves of arc-shaped permanent magnets. This paddle was built specifically to measure the intrinsic induction curves of the arc-magnets used in a specific linear alternator application. Because the magnets are arc-shaped, the $\mathrm{M}$ measurements were not expected to be accurate due to leakage flux at the curved ends of the magnets. However, the $\mathrm{H}_{\mathrm{ci}}$ measurements were expected to be reasonably accurate. The $\mathrm{H}_{\mathrm{ci}}$ measurement is helpful in estimating the approximate demagnetization temperatures for the actual magnets used in a given application.

A 2 to 3 percent distortion in the $\mathrm{H}_{\mathrm{ci}}$ measurement was expected due to the magnet's geometry. The magnetic field strength (H-field) is measured using a sensing coil. This coil can sense only the component of the H-field vector that is perpendicular to the plane of the coil winding. The shape of the arc-magnet sample likely caused some bending of the H-field, particularly along the edge of the magnet sample. This "edge effect" could reduce the measured $\mathrm{H}_{\mathrm{ci}}$ in comparison to the actual $\mathrm{H}_{\mathrm{c} i}$.

To verify the accuracy of the arc-magnet intrinsic coercivity measurements, two arc-magnet samples were first characterized, then sliced and stacked so that the stacked magnet sample could fit inside a standard 1-cm cubic magnet characterization fixture. Over the range of temperatures tested, the stacked magnet sample average intrinsic coercivity measurements were 8.6 percent higher than those for the arc-magnet samples.

Another potential cause of measurement error might be due to a non-uniformity of magnet sample demagnetization that increases with temperature. At least two factors could well be contributing to this error. First, the down-turning slope of the demagnetization curve, passing from the 2nd to 3rd quadrants in the $\mathrm{MH}$ plane, usually tends to steepen with increasing temperature. This means that for a small variation in $\mathrm{H}$, a large change in $\mathrm{M}$ may be induced. Second, the self-demagnetizing field becomes more significant relative to the reduced $\mathrm{H}_{\mathrm{ci}}$ at higher temperatures. Hence at higher temperatures, the non-uniformity of the self-demagnetizing field leads to increased non-uniformity of M. Such non-uniformity is sure to be present, because the curved sample is not in uniform contact with the flat pole faces of the electromagnet that applies the external (uniform) part of the demagnetizing field. 


\section{Apparatus and Procedure}

The apparatus required to measure the intrinsic coercivity of the arc-magnets is very similar to the apparatus described previously for magnet characterization of $1-\mathrm{cm}$ cubic magnet samples. The major difference is in the paddle (shown in Figure 8) used to hold the magnet sample between the pole faces of the electromagnet. The arcmagnet characterization paddle contains built-in magnetization and field sensing coils and can accommodate a single arc-magnet sample. The fixture and arc-magnet sample were positioned between the flat and parallel poles of the electromagnet. Due to the shape of the magnet, the surfaces of the magnet come into contact with the pole faces along three lines of contact rather than surface-to-surface contact. Two lines of contact are formed between the concave side of the magnet and one of the pole faces, while the third line of contact is formed between the convex side of the magnet and the other pole face, as shown in Figure 9. This feature of the arc-magnet intrinsic coercivity measurement apparatus is believed to be the reason for the inaccuracies in the arc-magnet $\mathrm{H}_{\mathrm{ci}}$ measurement. One possible way to correct this problem is to fabricate arc-shaped extensions for the electromagnet pole faces that facilitate surface-to-surface contact between the arc-magnet sample and the electromagnet pole faces.

The procedure used to measure the intrinsic coercivity of an arc-shaped magnet is identical to the procedure described earlier for magnet characterization. The only exception is that the arc-magnet characterization fixture is used rather than the standard characterization fixture.

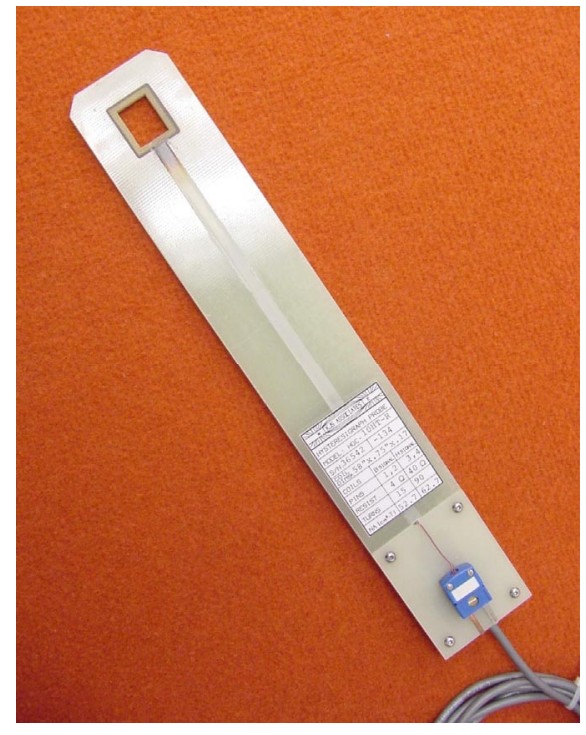

FIGURE 8. Arc-Magnet Characterization Paddle.

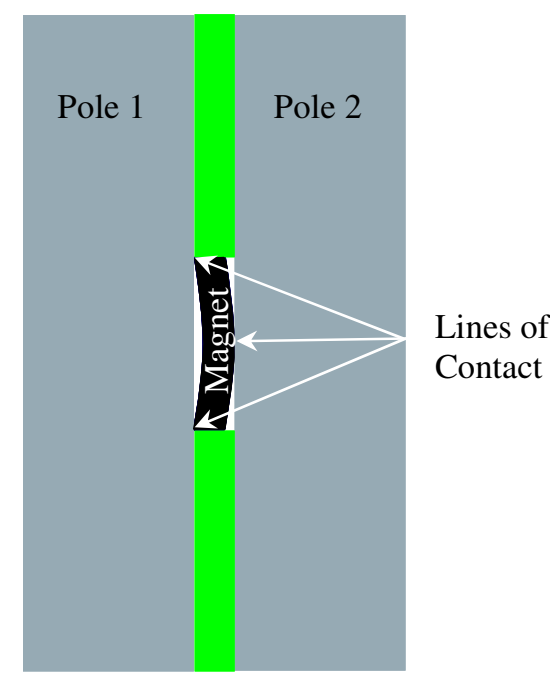

FIGURE 9. Arc-Magnet in Contact with Pole Faces.

\section{LINEAR ALTERNATOR CHARACTERIZATION}

An Alternator Test Rig (ATR) was assembled to facilitate research on low power $(<150 \mathrm{~W})$ linear alternators. The ATR can be used to perform a variety of tests on linear alternators. For example, the ATR can be used to map the performance of low power linear alternators over a range of temperatures, mover amplitudes, and alternator loads. In addition, it can also be used to evaluate alternator design margins in terms of magnetic saturation of the laminations and magnet demagnetization. A long-term goal is to use the ATR to better understand the losses associated with linear alternators. The information gained through these tests is intended to improve future linear alternator designs. 


\section{Apparatus and Procedure}

A linear alternator dynamometer (DTR0101) was purchased from Sunpower, Inc., and serves as the drive motor for the ATR. The DTR0101 is a variable stroke and variable frequency linear dynamometer of nominally $150 \mathrm{~W}$ output at $60 \mathrm{~Hz}$ and a $13 \mathrm{~mm}$ stroke, but can be driven at any frequency up to $120 \mathrm{~Hz}$. The dynamometer is driven using a Chroma model 6404 programmable AC source. A Sorensen model DCR80-6B DC power supply is used to provide power to an electric resistance heater tape which is wrapped around the test article to control temperature.

The data acquisition system used to record the linear alternator performance data was built using National Instruments hardware and LabVIEW software. The data acquisition system is used to acquire, display, and save data in comma-delimited text files that can be imported into Microsoft Excel for data reduction and analysis purposes. A Dell Precision model 450, $2 \mathrm{GHz}$ PC, coupled with a National Instruments PCI-MIO-16E-1, 12-bit, 16-channel multifunction data acquisition board, is the heart of the data acquisition system. An SCXI-1000, 4-slot chassis, connected to the data acquisition board, is equipped with two SCXI-1112, 8-channel thermocouple modules and two SCXI-1120, 8-channel isolation amplifiers.

The key instrumentation used in the ATR includes an RMS voltage transducer (Ohio Semitronics, model VT8-006X5), an RMS current transducer (Ohio Semitronics, model CT8-014X5), a power transducer (Ohio Semitronics, model PC8V-X5), and an instantaneous current monitor (Pearson, model 411). This instrumentation is connected to the output terminals of the alternator under test. A load cell (Kistler, model 9712B50) is mounted between the dynamometer and the test alternator to measure the alternator driving force. The load cell measurement is used to calculate the mechanical input power driving the test alternator. The alternator efficiency is calculated by dividing the alternator electrical output power by its mechanical input power.

The first test conducted using the ATR was a performance map test of a $55 \mathrm{We}$ linear alternator at steady-state conditions over a range of temperatures $\left(23\right.$ to $60{ }^{\circ} \mathrm{C}$ ), mover amplitudes (4 to $6 \mathrm{~mm}$ ), and linear alternator loads ( 80 to $160 \Omega$ ). Figure 10 shows the ATR with the test alternator mounted atop. Before the test began, the inductance of the linear alternator was measured and the capacitance required to tune the alternator was calculated. The appropriate capacitor was then wired in series with a decade box resistive load, which was connected to the output terminals of the linear alternator. The frequency of the alternator was maintained at the natural frequency of the alternator/drive motor system throughout the test. The temperature of the linear alternator stator was varied in increments of $20^{\circ} \mathrm{C}$. At each temperature increment, the alternator resistive load was varied in increments of $20 \Omega$. For each temperature and load combination, the

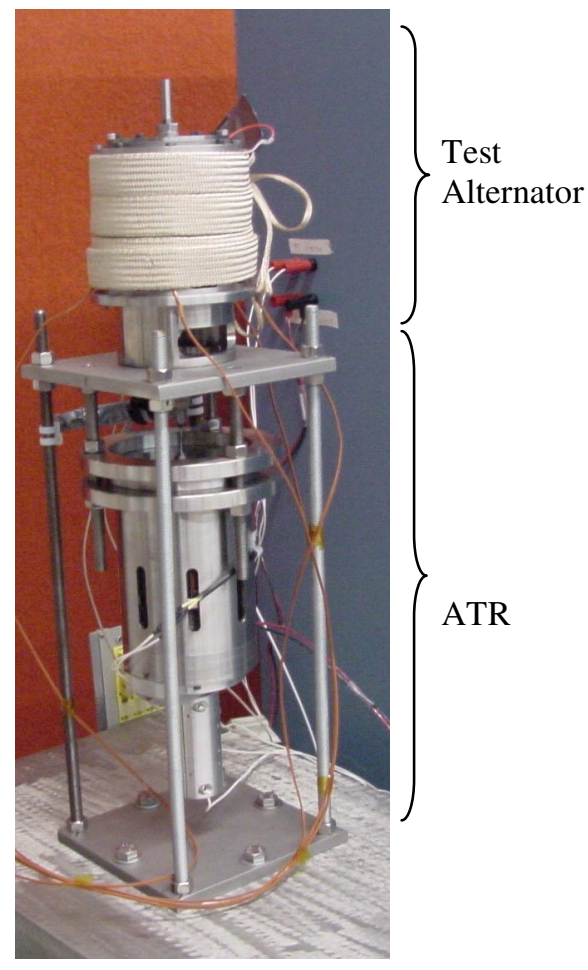

FIGURE 10. Alternator Test Rig (ATR). mover amplitude was varied in increments of one millimeter and a steady-state data point was recorded. Performance measurements made included the linear alternator terminal voltage, current, and output power. The alternator efficiency and power factor were then calculated from these measurements. The tuning capacitor was removed from the alternator load circuit and the entire test was repeated using just the resistive load. This was done to determine the effect of the tuning capacitor on alternator output power and efficiency.

\section{FUTURE PLANS}

The future plan is to continue aging tests on other grades of Nd-Fe-B magnets of interest to the Stirling convertor application and to possibly begin aging tests on selected grades of Sm-Co type magnets, using the second magnet aging fixture. The ATR may be used to evaluate the thermal and alternator load effects on magnets in specific linear 
alternator applications to validate analytical techniques used to predict demagnetization. Also, the ATR can be used to map the performance of various competing linear alternator designs for a more thorough comparison.

\section{CONCLUDING REMARKS}

NASA Glenn is conducting in-house research on permanent magnets and on linear alternators to assist in the development of Stirling convertors for space qualification and mission implementation and for developing advanced technology. Recent permanent magnet research efforts include magnet characterization and magnet aging tests on various grades of Neodymium-Iron-Boron type magnets. Linear alternator research efforts have begun just recently with the performance mapping of a moving-iron type linear alternator over a range of temperatures, mover amplitudes, and alternator loads. Information generated through this in-house effort has contributed to a better understanding of Stirling linear alternators.

\section{NOMENCLATURE}

$\begin{array}{ll}\text { ATR } & \text { Alternator Test Rig } \\ \mathrm{B} & \text { Magnetic Flux Density, }(\mathrm{G}) \\ \mathrm{B}_{\mathrm{r}} & \text { Remanence } \\ \mathrm{B}-\mathrm{H} & \text { Normal Induction } \\ \mathrm{DOE} & \text { Department of Energy } \\ \mathrm{GRC} & \text { Glenn Research Center } \\ \mathrm{H} & \text { Magnetic Field Strength, (Oe) } \\ \mathrm{H}_{\mathrm{c}} & \text { Coercivity } \\ \mathrm{H}_{\mathrm{ci}} & \text { Intrinsic Coercivity } \\ \mathrm{LM} & \text { Lockheed Martin } \\ \mathrm{M} & \text { Magnetization, }(\mathrm{G}) \\ \mathrm{M}-\mathrm{H} & \text { Intrinsic Induction } \\ \mathrm{Nd}-\mathrm{Fe}-\mathrm{B} & \text { Neodymium-Iron-Boron } \\ \text { REPM } & \text { Rare Earth Permanent Magnet } \\ \mathrm{Sm}-\mathrm{Co} & \text { Samarium-Cobalt } \\ \text { SRG110 } & \text { 110 Watt Stirling Radioisotope Generator } \\ \text { STC } & \text { Stirling Technology Company }\end{array}$

\section{REFERENCES}

Cockfield, R.D. and Chan, T.S., "Stirling Radioisotope Generator for Mars Surface and Deep Space Missions," Proceedings of 37th Intersociety Energy Conversion Engineering Conference, Washington, D.C., IECEC 2002 Paper No. $20188,2002$.

Niedra, J. M., and Schwarze, G. E., "Makeup and Uses of a Basic Magnet Laboratory for Characterizing High-Temperature Permanent Magnets," NASA TM-104508, 1991.

Niedra, J. M., "Short-term Aging of NdFeB Magnets for Stirling Linear Alternator Applications," NASA CR-2001-210952, 2001.

Schreiber, J.G. and Thieme, L.G., "Accomplishments of the NASA GRC Stirling Technology Development Project," Proceedings of 2nd International Energy Conversion Engineering Conference, Providence, RI, Paper No. AIAA 2004-5517, 2004. 


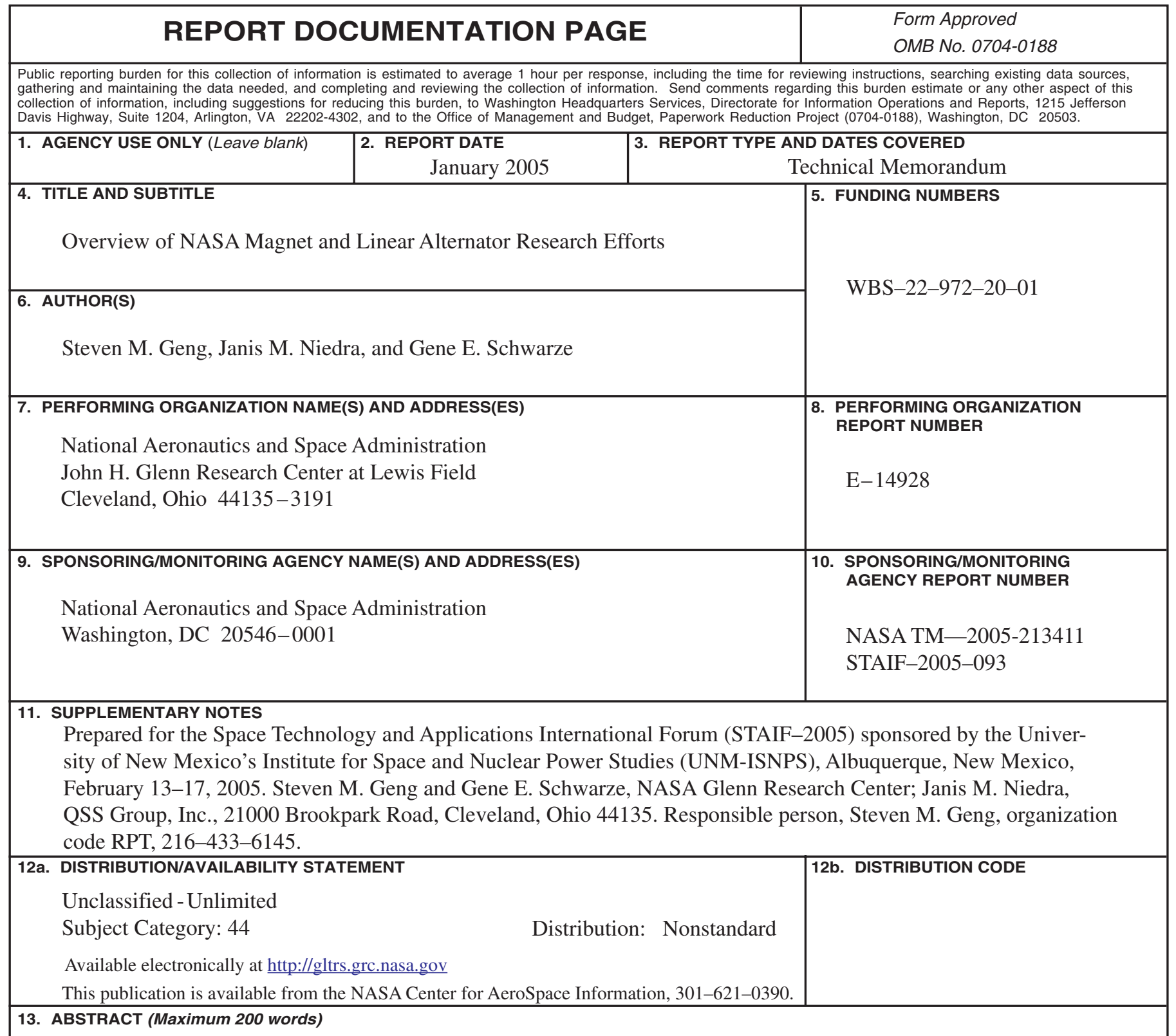

The Department of Energy, Lockheed Martin, Stirling Technology Company, and NASA Glenn Research Center are developing a high-efficiency, 110 watt Stirling Radioisotope Generator (SRG110) for NASA Space Science missions. NASA Glenn is conducting in-house research on rare earth permanent magnets and on linear alternators to assist in developing a free-piston Stirling convertor for the SRG110 and for developing advanced technology. The permanent magnet research efforts include magnet characterization, short-term magnet aging tests, and long-term magnet aging tests. Linear alternator research efforts have begun just recently at GRC with the characterization of a moving iron type linear alternator using GRC's alternator test rig. This paper reports on the progress and future plans of GRC's magnet and linear alternator research efforts.

\begin{tabular}{|c|c|c|c|}
\hline \multicolumn{3}{|l|}{ 14. SUBJECT TERMS } & 15. NUMBER OF PAGES \\
\hline \multicolumn{3}{|c|}{ Stirling engines; Stirling cycle; Linear alternators; Permanent magnets } & \begin{tabular}{|r}
14 \\
\end{tabular} \\
\hline $\begin{array}{l}\text { 17. SECURITY CLASSIFICATION } \\
\text { OF REPORT }\end{array}$ & $\begin{array}{l}\text { 18. SECURITY CLASSIFICATION } \\
\text { OF THIS PAGE }\end{array}$ & $\begin{array}{l}\text { 19. SECURITY CLASSIFICATION } \\
\text { OF ABSTRACT }\end{array}$ & 20. LIMITATION OF ABSTRACT \\
\hline Unclassified & Unclassified & Unclassified & \\
\hline
\end{tabular}



